\title{
Mitochondrial Trifunctional Protein Deficiency Catalytic Heterogeneity of the Mutant Enzyme in Two Patients
}

\author{
Takehiko Kamijo, * Ronald J. A. Wanders, " Jean-Marie Saudubray, "Toshifumi Aoyama," \\ Atsushi Komiyama, " and Takashi Hashimoto" \\ * Department of Pediatrics, Shinshu University School of Medicine, Matsumoto, Nagano 390, Japan; ${ }^{\ddagger}$ Department of Clinical \\ Biochemistry, University Hospital Amsterdam, Meibergdreef 9, Amsterdam, The Netherlands; ${ }^{\S}$ Clinique de Génétique Médicle, \\ Hopital Necker-Enfants Malades, Paris, France; and "Department of Biochemistry, Shinshu University School of Medicine, \\ Matsumoto, Nagano 390, Japan
}

\begin{abstract}
We examined the enzyme protein and biosynthesis of human trifunctional protein harboring enoyl-CoA hydratase, 3-hydroxyacyl-CoA dehydrogenase, and 3-ketoacyl-CoA thiolase activity in cultured skin fibroblasts from two patients with longchain 3-hydroxyacyl-CoA dehydrogenase deficiency. The following results were obtained. (a) In cells from patient 1 , immunoblot analysis and pulse-chase experiments indicated that the content of trifunctional protein was $<10 \%$ of that in control cells, due to a very rapid degradation of protein newly synthesized in the mitochondria. The diminution of trifunctional protein was associated with a decreased activity of enoyl-CoA hydratase, 3-hydroxyacyl-CoA dehydrogenase, and 3-ketoacylCoA thiolase, when measured using medium-chain to long-chain substrates. (b) In cells from patient 2 , the rate of degradation of newly synthesized trifunctional protein was faster than that in control cells, giving rise to a trifunctional protein amounting to $60 \%$ of the control levels. The 3-hydroxyacyl-CoA dehydrogenase activity with medium-chain to longchain substrates was decreased drastically, with minor changes in activities of the two other enzymes. These data suggest a subtle abnormality of trifunctional protein in cells from patient 2. Taken together, the results obtained show that in both patients, long-chain 3-hydroxyacyl-CoA dehydrogenase deficiency is caused by an abnormality in the trifunctional protein, even though there is a heterogeneity in both patients. ( J. Clin. Invest. 1994. 93:1740-1747.) Key words: mitochondria $\bullet$ fatty acids • oxidation • multienzyme complex • inborn error
\end{abstract}

\section{Introduction}

Mitochondrial fatty acid $\beta$-oxidation is a major energy-producing pathway. In recent years, an increasing number of hereditary defects of mitochondrial fatty acid $\beta$-oxidation has been reported (1-3). Depending upon the precise enzyme defect, the patients may present with a wide range of clinical features, including myopathy, cardiomyopathy, cardiac arrest, ventricular arrhythmia, hepatomegaly, and fasting coma with hypoke-

Address correspondence to Dr. Takehito Kamijo, Department of Pediatrics, Shinshu University School of Medicine, Matsumoto, Nagano 390, Japan.

Received for publication 14 June 1993 and in revised form 19 November 1993.

J. Clin. Invest.

(c) The American Society for Clinical Investigation, Inc.

0021-9738/94/04/1740/08 \$2.00

Volume 93, April 1994, 1740-1747 totic hypoglycemia. Such being the case, these patients may sometimes be misdiagnosed or even considered to be victims of sudden infant death syndrome or Reye syndrome.

Long-chain 3-hydroxyacyl-CoA dehydrogenase deficiency has been identified as a disorder of mitochondrial fatty acid $\beta$-oxidation. This defect was first suspected in a patient with massive amounts of long-chain 3-hydroxydicarboxylic acids in the urine during a period of acute decompensation. Earlier studies revealed that mitochondria, at least from the rat, contain two distinct 3-hydroxyacyl-CoA dehydrogenases, one located in the mitochondrial matrix with preference for shortchain 3-hydroxyacyl-CoA esters $(4,5)$, and the other membrane bound, preferentially reacting with long-chain substrates and therefore called long-chain 3-hydroxyacyl-CoA dehydrogenase (6). When the 3-hydroxyacyl-CoA dehydrogenase activity of the patients' fibroblasts was assayed, the activity with long- but not short-chain substrates was significantly lower. This disease was therefore named long-chain 3-hydroxyacylCoA dehydrogenase deficiency. About 20 patients with this disorder have been described (7-10) since the first report in 1989 (11).

Mitochondrial long-chain 3-hydroxyacyl-CoA dehydrogenase from rat liver was recently purified (12). Surprisingly, this activity was found to be part of a multienzyme complex also harboring enoyl-CoA hydratase and 3-ketoacyl-CoA thiolase activity; it was therefore named mitochondrial trifunctional protein (TP). ${ }^{1}$ This enzyme is a heterooctamer consisting of four moles of the large $(\alpha)$ subunit and four moles of the small ( $\beta$ ) subunit. The $\alpha$ subunit of rat mitochondrial trifunctional protein is assumed to possess enoyl-CoA hydratase and 3-hydroxyacyl-CoA dehydrogenase activities, while the $\beta$ subunit has 3-ketoacyl-CoA thiolase activity, as deduced from primary structures of the nucleotide sequences of the cloned cDNAs (13). Mitochondrial trifunctional protein also purified from human liver revealed that the human and rat enzymes are similar with respect to molecular and catalytic properties (14).

We report here the molecular and catalytic properties of mitochondrial trifunctional protein in fibroblasts from controls and from two patients with long-chain 3-hydroxyacylCoA dehydrogenase deficiency. We compared the data obtained with human mitochondrial trifunctional protein (human-TP), as purified from human liver, using a procedure similar to that described for the rat enzyme (12). The availability of antibodies toward human-TP as well as antibodies against short-chain enoyl-CoA hydratase, short-chain 3-hydroxyacyl-CoA dehydrogenase, and mitochondrial 3-ketoacyl-

1. Abbreviations used in this paper: TP, mitochondrial trifunctional protein. 
CoA thiolase facilitated these studies. The long-chain 3-hydroxyacyl-CoA dehydrogenase deficiency is, indeed, due to the functional loss of this component of the human-TP. These studies also show that, in this disease, there is heterogeneity in the causation of mitochondrial trifunctional protein malfunction.

\section{Methods}

Materials. Fatty acids were purchased from Sigma Chemical Co. (St. Louis, MO), and Tokyo Kasei (Tokyo, Japan). DEAE-cellulose was from Seikagaku Kogyo (Tokyo, Japan), phosphocellulose was from Whatman (Maidstone, England), Ultrogel AcA 34 was from IBF biotechnics (Vileneuve-la-Garenne, France), and affinity adsorbent was from Boehringer Mannheim GmbH (Mannheim, Germany). Proteins used as molecular mass markers for SDS-PAGE were obtained from Bio-Rad Laboratories (Richmond, CA).

$\left[{ }^{35}\right.$ S $]$ Methionine was from Du Pont/NEN Research Products (Boston, MA ). Amplify ${ }^{\circledR}$ was from Amersham (Buckinghamshire, England), the fixed Staphylococcus aureus cells were from CalbiochemBehring Corp. (San Diego, CA). All the other reagents were of the purest analytical grade available.

Mitochondrial short-chain acyl-CoA dehydrogenase (15), medium-chain acyl-CoA dehydrogenase (15), long-chain acyl-CoA dehydrogenase (15), very long-chain acyl-CoA dehydrogenase (16), mitochondrial short-chain enoyl-CoA hydratase (17), mitochondrial shortchain 3-hydroxyacyl-CoA dehydrogenase $(4,5)$, mitochondrial short-chain 3-ketoacyl-CoA thiolase (18), peroxisomal 3-ketoacylCoA thiolase (18), and peroxisomal bifunctional protein (19) were purified from rat liver and the antibodies were raised in rabbits, as described. The antibodies were immunopurified with the use of immunoadsorbent columns that were coupled with the enzymes, as described in the instructions from the manufacturer.

We used skin fibroblasts from two patients with long-chain 3-hydroxyacyl-CoA dehydrogenase deficiency. These fibroblasts were grown in Eagle's minimum essential medium containing $10 \%$ fetal calf serum ( $\mathrm{vol} / \mathrm{vol}$ ) and antibiotics. The cells were used for study 3-4 d after confluence. Findings in the first patient (patient 1) have been described elsewhere (20). This patient presented on the 2 nd postnatal day with severe hypotonia and hypoglycemia and died of cardiac failure on the 30th day, despite intensive therapy. The second patient (patient 2) presented early in life with hypoketotic hypoglycemia and a marked 3-hydroxy dicarboxylic aciduria. A defect of mitochondrial $\beta$-oxidation at the level of long-chain 3-hydroxyacyl-CoA dehydrogenase was suspected by findings of decreased $\left[1-{ }^{14} \mathrm{C}\right]$ palmitic acid oxidation in the skin fibroblasts, and this tentative diagnosis was confirmed by assay of the enzyme activity.

Preparation of substrates. Acetoacetyl-CoA was prepared with $\mathrm{CoA}$ and diketene (21). Crotonyl-CoA was prepared by the method of Steinman and Hill (22). 2-Hexadecenoyl-CoA, 2-dodecenoyl-CoA, and 2-octenoyl-CoA were prepared by the mixed anhydride method (23). 2-Enoyl-CoAs were converted to 3-ketoacyl-CoAs with use of the fatty acid oxidation multienzyme complex of Pseudomonas fragi (24).

Enzyme assays. The enoyl-CoA hydratase activity was assayed by a decrease in 2-enoyl-CoAs at $280 \mathrm{~nm}$ (17). The 3-hydroxyacyl-CoA dehydrogenase activity was measured by 3-ketoacyl-CoA-dependent NADH oxidation (4). The activity of 3-ketoacyl-CoA thiolase was assayed by the thiolytic reaction and after the absorbance at $303 \mathrm{~nm}$ (12). In the 3-ketoacyl-CoA thiolase assay with the $\mathrm{C} 12$ substrate, the following were used: medium $1,0.1 \mathrm{M}$ Tris- $\mathrm{Cl}, \mathrm{pH} 8.3,3 \mathrm{mM} \mathrm{MgCl}$, and 20 $\mu \mathrm{M}$ 3-ketododecanoyl-CoA; medium 2, $0.1 \mathrm{M}$ Tris-Cl, $\mathrm{pH} 8.3,25 \mathrm{mM}$ $\mathrm{MgCl}_{2}, 50 \mathrm{mM} \mathrm{KCl}, 0.1 \%$ Triton X-100 (wt/vol), $0.2 \mathrm{mg} / \mathrm{ml} \mathrm{BSA}$, and $10 \mu \mathrm{M}$ 3-ketododecanoyl-CoA. In the 3-ketoacyl-CoA thiolase assay with the $\mathrm{C} 16$ substrate, the following were used: medium $3,0.1 \mathrm{M}$ Tris-Cl, $\mathrm{pH} 8.3,1 \mathrm{mM} \mathrm{MgCl}$, and $20 \mu \mathrm{M}$ 3-ketohexadecanoyl-CoA; medium 4, $0.1 \mathrm{M}$ Tris-Cl, $\mathrm{pH} 8.3,25 \mathrm{mM} \mathrm{MgCl}_{2}, 50 \mathrm{mM} \mathrm{KCl}, 0.1 \%$ Triton X-100 (wt/vol), $0.2 \mathrm{mg} / \mathrm{ml} \mathrm{BSA}$, and $10 \mu \mathrm{M}$ 3-ketohexadecanoyl-CoA.
Purification of human-TP and preparation of polyclonal antibodies. TP was purified from a human liver obtained at autopsy by monitoring the 3-hydroxyacyl-CoA-dependent oxidation of NADH. These procedures were performed at $4^{\circ} \mathrm{C}$. The frozen liver $(25 \mathrm{~g})$ was homogenized in $125 \mathrm{ml}$ of $50 \mathrm{mM} \mathrm{K}_{2} \mathrm{HPO}_{4}$, containing $0.1 \%$ ( vol/ vol) hexamethylphosphoric triamide, $2 \mathrm{mM}$ 2-mercaptoethanol, $0.5 \mathrm{mM}$ EDTA, $1 \mathrm{mM}$ phenylmethylsulfonyl fluoride, and $1 \mathrm{mM}$ benzamidine. The mixture was centrifuged at $3,000 \mathrm{~g}$ for $5 \mathrm{~min}$, and the supernatant was centrifuged at $100,000 \mathrm{~g}$ for $60 \mathrm{~min}$. The pellet was homogenized with $40 \mathrm{ml}$

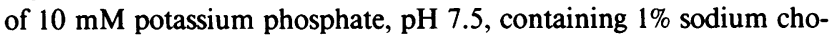
late, $0.5 \mathrm{M} \mathrm{KCl}, 0.1 \%$ (vol/vol) hexamethylphosphoric triamide, 2 $\mathrm{mM} 2$-mercaptoethanol, and $0.5 \mathrm{mM}$ EDTA. The mixture was kept on ice for $30 \mathrm{~min}$, and subsequently centrifuged at $20,000 \mathrm{~g}$ for $15 \mathrm{~min}$. The enzyme was purified by polyethylene glycol no. 6000 precipitation, DEAE-cellulose, and phosphocellulose column chromatography (12). About $2.5 \mathrm{mg}$ of TP was purified using this procedure.

Purified human-TP $(0.25 \mathrm{mg})$ was dialyzed against $0.15 \mathrm{M} \mathrm{NaCl}$ containing $10 \mathrm{mM}$ potassium phosphate $\mathrm{pH} 7.5$, and emulsified with Freund's complete adjuvant. The emulsion was injected into the axillary regions of a rabbit. Boosters, containing $0.1 \mathrm{mg}$ of purified humanTP in emulsion containing Freund's complete adjuvant were injected twice into subcutaneous sites on the dorsum, 4 and 6 wk later. Blood samples were taken from a carotid artery 2 wk after the last booster injection. The antibody was partially purified by fractionation with ammonium sulfate and dialyzed against $0.15 \mathrm{M} \mathrm{NaCl}$ containing 10 $\mathrm{mM}$ potassium phosphate, $\mathrm{pH}$ 7.5.

Extraction of enoyl-CoA hydratase, 3-hydroxyacyl-CoA dehydrogenase, and 3-ketoacyl-CoA thiolase activities in skin fibroblasts. For extraction of enoyl-CoA hydratase and 3-hydroxyacyl-CoA dehydrogenase activities, fibroblasts were sonicated in $25 \mathrm{mM}$ potassium phosphate, $\mathrm{pH} 7.5$, containing $0.2 \mathrm{M}$ sodium chloride, $0.1 \%$ ( $\mathrm{vol} / \mathrm{vol}$ ) hexamethylphosphoric triamide, $2 \mathrm{mM} 2$-mercaptoethanol, and 0.5 mM EDTA. We used $0.1 \mathrm{M}$ Tris-Cl, $\mathrm{pH} 8.3$, instead of $25 \mathrm{mM}$ potassium phosphate, $\mathrm{pH} 7.5$, for extraction of 3-ketoacyl-CoA thiolase activity. Tween $20(20 \%$ [ $\mathrm{vol} / \mathrm{vol}])$ was added to give a final concentration of $0.5 \%$ ( $\mathrm{vol} / \mathrm{vol}$ ). After incubation on ice for $30 \mathrm{~min}$, the homogenate was centrifuged at $18,000 \mathrm{~g}$ for $5 \mathrm{~min}$. The supernatant was used for enzyme assays. Immunoblot analysis using anti-( human-TP) antibody confirmed that the enzyme was completely extracted by the use of either of the two extraction buffers (not shown).

Immunotitration. Fibroblasts' extracts, prepared as described below, were mixed with fivefold the equivalent amounts of the anti-( rat mitochondrial short-chain enoyl-CoA hydratase) antibody, anti-(rat mitochondrial short-chain 3-hydroxyacyl-CoA dehydrogenase) antibody, and anti-( rat mitochondrial 3-ketoacyl-CoA thiolase) antibody, respectively. The mixtures were incubated for $1 \mathrm{~h}$ at $4^{\circ} \mathrm{C}$, then centrifuged at $18,000 \mathrm{~g}$ for $5 \mathrm{~min}$, and the supernatants were used for assay of the enzyme. The amounts of antibodies required to completely precipitate various enzyme proteins from the fibroblasts' extracts were determined by antibody titration monitoring residual enzyme activities in the supernatant fractions obtained after centrifugation.

Assay and analysis of protein. Protein concentration was determined by a modification (25) of the method of Lowry et al. (26). SDS-PAGE on a $10 \%$ gel was performed according to Laemmli (27).

Immunoblot analysis was made according to Towbin et al. (28) using an immunoblot system (Amersham Japan) for color development. The bands were quantified using a densitometer (Cliniscan $2^{\circledR}$; Helena, Beaumont, TX).

Pulse-chase experiments. The fibroblasts were grown in $20-\mathrm{cm}^{2}$ petri-dishes. Pulse labeling was performed as described (29) using $50 \mu \mathrm{Ci}$ of $\left[{ }^{35} \mathrm{~S}\right]$ methionine per dish. After a 1-h pulse, the medium was replaced by standard medium and the labeled fibroblasts were chased for 6 and $24 \mathrm{~h}$, respectively. The labeled cells were washed, collected, sonicated in an extraction buffer, and centrifuged. The supernatant was placed in boiling water for 3 min since the anti-(human-TP) antibody precipitated only the denatured human-TP. The labeled protein in the fibroblast extracts was immunoprecipitated with the anti-(human-TP) antibody and fixed Staphylococcus aureus cells. The recovered labeled 
products were subjected to SDS-PAGE and to fluorography. Competition experiments were done, using an excess amount of human-TP during the immunoprecipitation.

Rhodamine $6 \mathrm{G}$, an inhibitor of transport of the precursors of the mitochondrial enzymes and their processing (30), was added to some preparations of the culture medium to give a final concentration of 2 $\mathrm{mg} / \mathrm{ml} 30 \mathrm{~min}$ after start of the preincubation, and to the labeling medium, as described (31). The fibroblasts were then labeled and the enzyme was extracted as described above.

\section{Results}

Molecular and catalytic properties of human mitochondrial trifunctional protein. Fig. 1 shows the carbon chain length specifities of the three components of human-TP, i.e., enoyl-CoA hydratase, 3-hydroxyacyl-CoA dehydrogenase, and 3-ketoacylCoA thiolase. All three activities showed a preference for the long-chain substrates, as compared with the short-chain ones. The carbon chain length specificity of human-TP was similar to that of rat mitochondrial trifunctional protein (12).

The molecular mass of native human-TP was estimated to be $507 \mathrm{kD}$ by gel filtration (Ultrogel AcA 34), using the same buffer as that used for rat enzyme (12) (not shown). HumanTP consisted of two subunits, and molecular weights were estimated to be 74,000 and 50,000 for the $\alpha$ and $\beta$ subunits, respectively, by SDS-PAGE, and Coomassie blue staining (Fig. 2). These data indicate that human-TP is a heterooctamer with the $\alpha 4 \beta 4$ structure.

Enzyme activities in cultured skin fibroblasts. Table I shows measurements of enzyme activity in fibroblasts' extracts

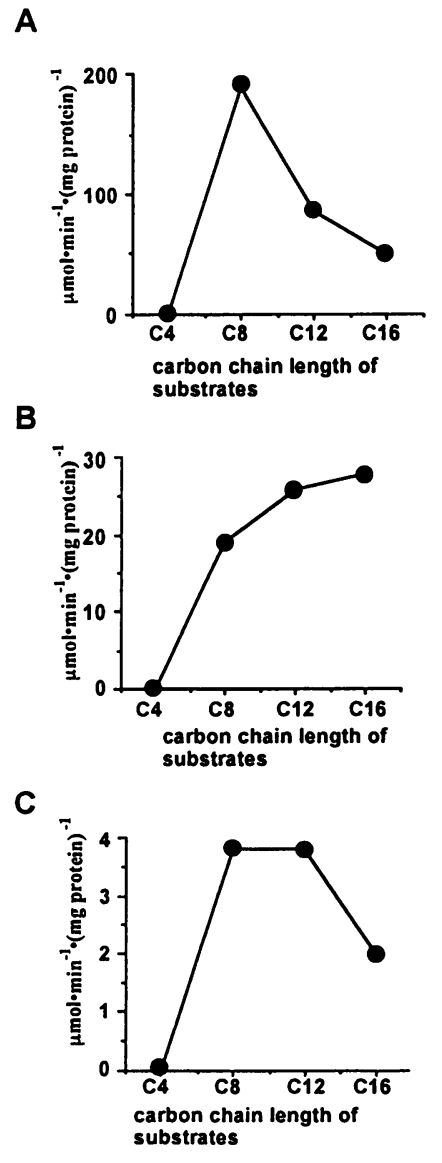

Figure 1. Carbon chain length specifities of purified humanTP. (A) Enoyl-CoA hydratase; (B) 3-hydroxyacyl-CoA dehydrogenase; $(C)$ 3-ketoacyl-CoA thiolase. The enoyl-CoA hydratase, 3-hydroxyacyl-CoA dehydrogenase, and 3-ketoacyl-CoA thiolase activities were measured as described in Methods. We used mediums 1 and 3 for the 3-ketoacyl-CoA thiolase activities with the $\mathrm{C} 12$ and $\mathrm{C} 16$ substrates, respectively. The activities were expressed as $\mu \mathrm{mol} / \mathrm{min}$ per $\mathrm{mg}$ protein.
Table I. Activities of Fatty Acid $\beta$ Oxidation Enzymes in Cultured Skin Fibroblasts

\begin{tabular}{lccc}
\hline & $\begin{array}{c}\text { Patient } \\
1\end{array}$ & $\begin{array}{c}\text { Patient } \\
2\end{array}$ & Control \\
\hline $\begin{array}{l}\text { Enoyl-CoA hydratase } \\
\quad \text { activity }\end{array}$ & & & \\
$\begin{array}{l}\text { Crotonyl-CoA } \\
\text { 3-Ketohexadecenoyl-CoA }\end{array}$ & 183.4 & 193.5 & $198.1 \pm 46.3(n=6)$ \\
$\begin{array}{l}\text { 3-hydroxyacyl-CoA } \\
\text { dehydrogenase activity }\end{array}$ & 52.0 & $69.3 \pm 15.0(n=6)$ \\
$\begin{array}{c}\text { Acetoacetyl-Coa } \\
\text { 3-Ketohexadecanoyl-CoA }\end{array}$ & 24.4 & 17.9 & $20.7 \pm 4.9(n=6)$ \\
$\begin{array}{c}\text { 3-Ketoacyl-CoA thiolase } \\
\quad \text { activity }\end{array}$ & $5.6^{*}$ & $18.8 \pm 2.7(n=6)$ \\
$\begin{array}{c}\text { Acetoacetyl-CoA } \\
\text { 3-Ketohexadecanoyl-CoA } \\
\text { (medium 3) }\end{array}$ & 14.3 & 13.0 & $10.2 \pm 2.3(n=6)$ \\
$\begin{array}{l}\text { 3-Ketohexadecanoyl-CoA } \\
\text { (medium 4) }\end{array}$ & $3.9^{*}$ & 5.1 & $7.1 \pm 1.1(n=4)$ \\
\hline & $0.0^{*}$ & $6.8^{*}$ & $16.4 \pm 3.3(n=4)$ \\
\hline
\end{tabular}

Enzyme activities were assayed using substrates with different lengths of carbon chain. The activities are expressed as $\mathrm{nmol} / \mathrm{min}$ per $\mathrm{mg}$ protein. The values of the control are the mean $\pm \mathrm{SD}$. * The values are lower than mean -2 SD of the respective control values. We used mediums 3 and 4 for the 3-ketoacyl-CoA thiolase activity with the $\mathrm{C} 16$ substrate.

from controls and from two patients. Activities were measured using both short- and long-chain substrates.

In fibroblasts from patient 1 , the enoyl-CoA hydratase, 3hydroxyacyl-CoA dehydrogenase, and 3-ketoacyl-CoA thiolase activities, as measured with the C16 substrates, were 45 , 42 , and $0 \%$ of the control mean, respectively (thiolase activity with $\mathrm{C} 16$ substrate was assayed with the medium 4). These values are all below the control mean $-2 \mathrm{SD}$.

Table I also shows that when the same activities were measured in fibroblasts from patient 2 , the values were 75,30 , and $42 \%$ of the control mean, respectively, (thiolase activity with C16 substrate was assayed with the medium 4 ). These values

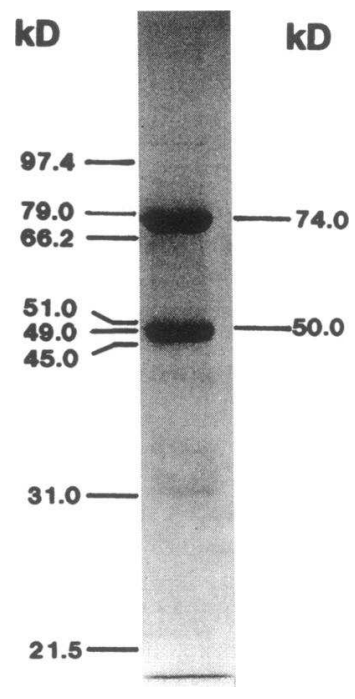

Figure 2. SDS-PAGE of purified human-TP. The purified enzyme $(2 \mu \mathrm{g})$ was subjected to SDS-PAGE on a $10 \%$ gel and stained with Coomassie brilliant blue R-250. The molecular masses of the large and small subunits were estimated to be 74 and $50 \mathrm{kD}$, respectively. Proteins used as molecular mass standards were rabbit muscle phosphorylase $b(97.4 \mathrm{kD})$, bovine serum albumin $(66.2 \mathrm{kD})$, hen egg white ovalbumin $(45.0 \mathrm{kD})$, bovine carbonic anhydrase (31.0 kD), soybean trypsin inhibitor ( $21.5 \mathrm{kD})$, and rat mitochondrial trifunctional protein (large subunit, $M_{\mathrm{r}} 79,000$, small subunit, $M_{\mathrm{r}} 49,000$ ) 
are all lower than the control mean $-1 \mathrm{SD}$, except for the long-chain 3-hydroxyacyl-CoA dehydrogenase activity, as measured with the $\mathrm{Cl} 6$ substrate that was below the mean control -2 SD value.

In the presence of $1 \mathrm{mM} \mathrm{Mg}^{2+}$ concentration (medium 3), the assay of the thiolase activity with the $\mathrm{C} 16$ substrate showed comparable results between patient 2 and control values. However, the assay of the same activity using medium with $25 \mathrm{mM}$ $\mathrm{Mg}^{2+}$ concentration and $0.1 \%$ Triton X-100 (medium 4) revealed a decreased thiolase activity in patient 2 . The thiolase activities measured in cells of patient 1 were low, under both experimental conditions. We attribute these results to activation of the thiolase activity of the trifunctional protein and to inhibition of the other 3-ketoacyl-CoA thiolases. In our report on the purification of rat trifunctional protein (12), we described the effects of $\mathrm{pH}$ and detergent on short-chain 3-hydroxyacyl-CoA dehydrogenase and trifunctional protein. Values for the 3-ketoacyl-CoA thiolase activity of the purified human trifunctional protein toward the $\mathrm{C} 12$ substrate with medium 2 and the $\mathrm{C} 16$ substrate with medium 4 were $\sim 5$-fold and $\sim 10$-fold higher, respectively, (data not shown). As purified human mitochondrial short-chain 3-ketoacyl-CoA thio-

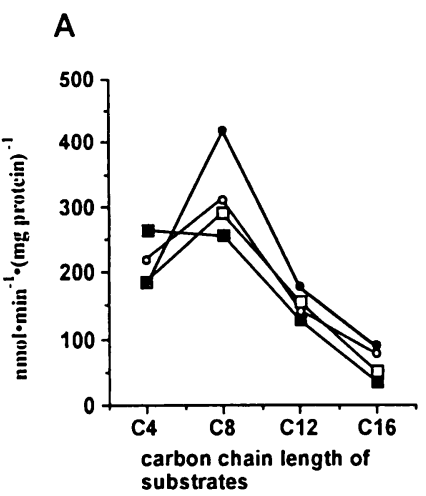

$$
\text { B }
$$

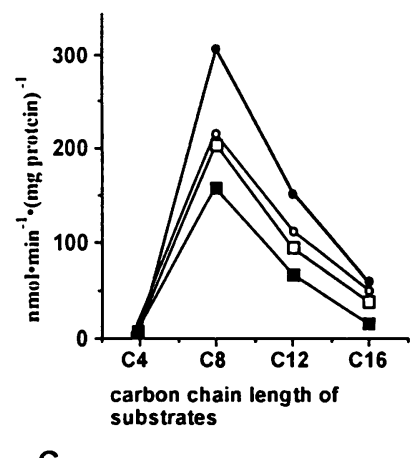

C

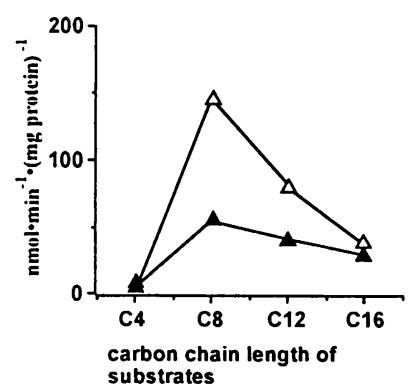

Figure 3. Carbon chain length specificities of enoyl-CoA hydratase activities in fibroblast extracts. The activities were measured before $(A)$ and after $(B)$ immunoprecipitation of mitochondrial short-chain enoyl-CoA hydratase, and expressed as $\mathrm{nmol} / \mathrm{min}$ per $\mathrm{mg}$ protein. Controls 1 and $2(\bullet$ and $O$ ); patient $1(-)$; and patient 2 (ם). Differences in the value after immunoprecipitation between control 1 and patient $1(\Delta)$ and that between control 2 and patient $1(\Delta)$ were plotted $(C)$. lase and human peroxisomal short-chain 3-ketoacyl-CoA thiolase are not yet available, we cannot predict at this time what effect different $\mathrm{Mg}^{+}$concentrations would have on the catalytic activity of these enzymes.

To obtain more information on the significance and interpretation of the data in Table I, the mitochondrial monofunctional enzymes were immunoprecipitated and the residual activities were measured. Fig. 3 shows data from an experiment in which enoyl-CoA hydratase activities were measured using a series of substrates in fibroblasts' extracts, either untreated or treated with an antibody raised against mitochondrial enoylCoA hydratase (crotonase). The results show that immunoprecipitation of mitochondrial enoyl-CoA hydratase led to a virtually complete disappearance of activity, as measured with the C4 substrate, both in the control and in fibroblasts from the two patients. The amount of human-TP in cells from patient 1 was little, as described below (see Fig. 6), and no significant contribution of peroxisomal bifunctional protein was expected from the remaining enoyl-CoA hydratase activity, based on the very low content of peroxisomal bifunctional protein in fibroblasts estimated by immunoblot analysis. Therefore, we think that the residual enoyl-CoA hydratase activity in fibroblasts from patient 1 , especially as measured with $\mathrm{C} 8$ and $\mathrm{C} 12$ substrates, is due to a distinct enoyl-CoA hydratase with preference for medium-chain substrates. The existence of yet another $\beta$ oxidation enzyme with medium-chain enoyl-CoA hydratase activity has been postulated (32), and we are currently characterizing this protein. Indeed, this substrate specificity differed from that of the purified human mitochondrial short-chain enoyl-CoA hydratase, peroxisomal bifunctional protein, and human-TP. The ratio $(\mathrm{C} 4 / \mathrm{C} 8)$ of the activities with $\mathrm{C} 4$ and $\mathrm{C} 8$ of mitochondrial short-chain enoyl-CoA hydratase and peroxisomal bifunctional protein was $\sim 2$ and 0.4 , respectively (our unpublished observation). Differences between activities in the controls and in patient 1 after immunoprecipitation (Fig. 3 $B$ ) are plotted in Fig. $3 C$. The carbon chain length specificity in Fig. $3 C$ was similar to that of purified human-TP (Fig. $1 A$ ).

When the fibroblast extracts were treated with the anti-( $\mathrm{mi}-$ tochondrial short-chain 3-hydroxyacyl-CoA dehydrogenase) antibody, the 3-hydroxyacyl-CoA dehydrogenase activity with the $\mathrm{C} 4$ substrate was markedly reduced, and the residual 3-hydroxyacyl-CoA dehydrogenase activities with medium-chain to long-chain substrates in the patients' cells were $<20 \%$ of those in the control cells (Fig. 4, $A$ and $B$ ). The difference between the activities in control fibroblasts and fibroblasts from patient 1 after immunoprecipitation (Fig. $4 \mathrm{~B}$ ) are represented in Fig. $4 C$. The results show that the carbon chain length specificity, as observed in Fig. $4 C$, was similar to that of purified human-TP (Fig. $1 B$ ).

After treatment of the fibroblasts' extracts with the anti-(mitochondrial 3-ketoacyl-CoA thiolase) antibody, residual 3-ketoacyl-CoA thiolase activities were measured with the $\mathrm{C} 4, \mathrm{C} 8, \mathrm{C} 12$, and $\mathrm{C} 16$ substrates (Fig. $5 B$ ). In Fig. 5, $A-C$, thiolase activities with the $\mathrm{C} 12$ and $\mathrm{C} 16$ substrates were determined using media 2 and 4, respectively. The residual 3-ketoacyl-CoA thiolase activity with the $\mathrm{C} 4$ substrate may be due to mitochondrial and/or cytosolic acetoacetyl-CoA thiolase. There was no 3-ketoacyl-CoA thiolase activity in cells from patient 1 . In cells from patient 2 , the residual 3-ketoacyl-CoA thiolase with the $\mathrm{C} 16$ substrate was $42 \%$ of that found in control cells. Since the content of human-TP in cells from patient 1 
was very low, the residual 3-ketoacyl-CoA thiolase activities with the medium-chain substrates may be partly due to peroxisomal 3-ketoacyl-CoA thiolase (Fig. $5 B$ ). Differences in the activities, as measured in control and patient 1 fibroblasts after immunoprecipitation (Fig. $5 \mathrm{~B}$ ), are given in Fig. $5 \mathrm{C}$. The carbon chain length specificity in Fig. $5 C$ was dissimilar to that of purified human-TP (Fig. $1 C$ ) since different medium was used for the thiolase assay.

Immunoblot analysis. Fig. 6 shows the results of immunoblot analysis with the anti-(human-TP) antibody. The mobilities of $\alpha$ and $\beta$ subunits, as present in fibroblasts, differ somewhat as compared with the mobility observed with purified human-TP (compare lane 1 with lanes 2 and 3 ). Subsequent studies showed this to be due to differences in ionic composition of the samples. In a separate experiment, we confirmed by examination of the mobilities of a mixture of the fibroblast extract and the purified enzyme that the purified human-TP and the human-TP in skin fibroblasts have the same mobility. The signal bands of both $\alpha$ and $\beta$ subunits of human-TP in skin fibroblasts were quantified by densitometry. The ratios of intensities of $\alpha$ and $\beta$ subunits were nearly the same as those of
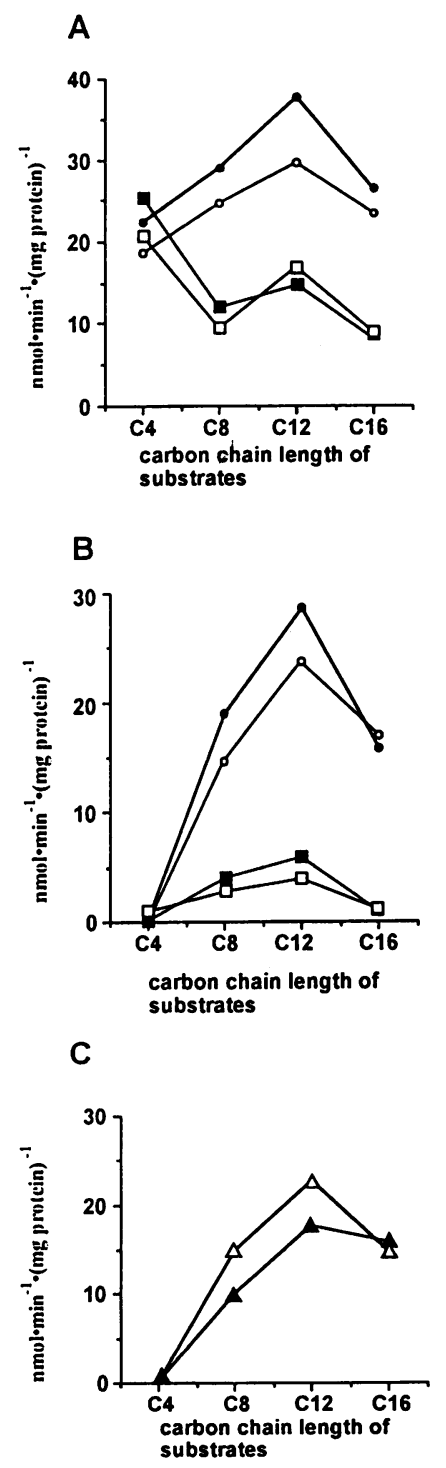

Figure 4. Carbon chain length specificities of 3-hydroxyacylCoA dehydrogenase activities in fibroblast extracts. The activities were measured before $(A)$ and after $(B)$ immunoprecipitation of mitochondrial short-chain 3-hydroxyacylCoA dehydrogenase, and expressed as $\mathrm{nmol} / \mathrm{min}$ per $\mathrm{mg}$ protein. Controls 1 and 2 (• and $O)$; patient 1 (a); and patient 2 (ם). Differences in the value after immunoprecipitation between control 1 and patient $1(\Delta)$ and that between control 2 and patient $1(\Delta)$ were plotted $(C)$.
A

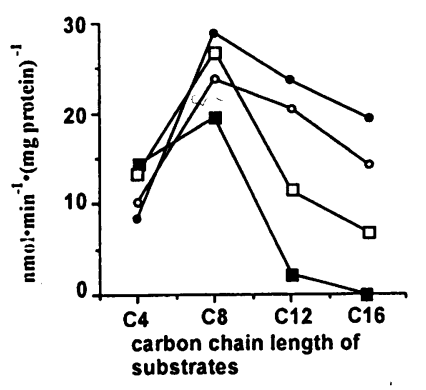

B
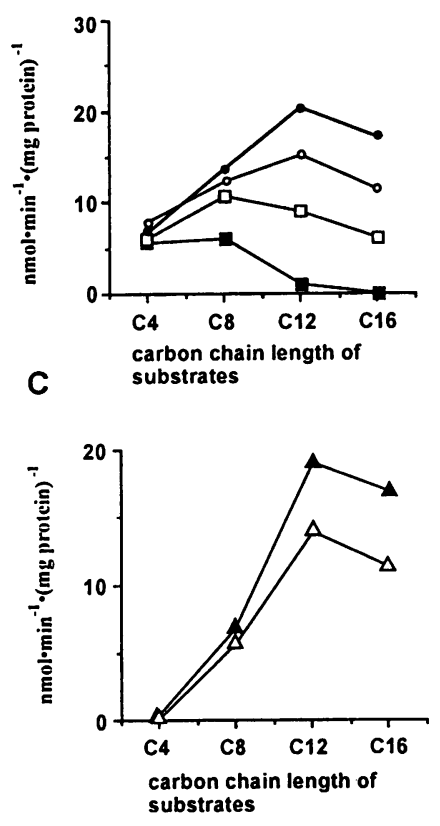

Figure 5. Carbon chain length specificities of 3-ketoacyl-CoA thiolase activities in fibroblast extracts. The activities were measured before $(A)$ and after $(B)$ immunoprecipitation of mitochondrial 3-ketoacyl-CoA thiolase, and expressed as $\mathrm{nmol} / \mathrm{min}$ per $\mathrm{mg}$ protein. Controls 1 and 2 (• and 0 ); patient $1(\square)$; and patient 2 (ם). Differences in the value after immunoprecipitation between control 1 and patient 1 $(\Delta)$ and that between control 2 and patient $1(\Delta)$ were plotted $(C)$. We used mediums 2 and 4 for the 3-ketoacyl-CoA thiolase activities with the $\mathrm{C} 12$ and C16 substrates, respectively.

the purified enzyme preparation, and the content of humanTP in the two cell lines (Fig. 6, lanes 2 and 3) was estimated to be $\sim 0.07 \%$ of total protein of the control fibroblasts.

No difference in the mobilities of the $\alpha$ and $\beta$ subunits in the patients' cells could be detected. In cells from patient 1 (Fig. 6, lanes 4 and 5), the intensity of the signal for the $\alpha$ subunit was $<5 \%$ of that in control cells, whereas the signal for the $\beta$ subunit was hardly detectable. In cells from patient 2 (Fig. 6, lanes 6 and 7), the intensities of both signals were $\sim 60 \%$ of those of the control, thereby suggesting the presence of virtually normal mitochondrial trifunctional protein in cells from patient 2 , in agreement with the data in Table $I$.

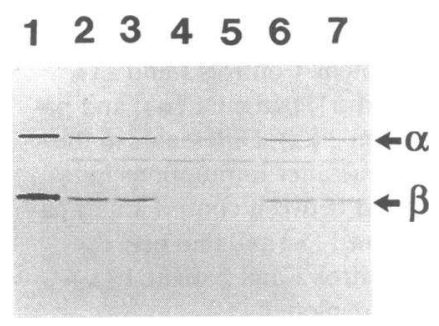
of human-TP. Lane 1 , purified human-TP ( $20 \mathrm{ng})$; lanes 2 and 3, control fibroblasts (20 $\mu \mathrm{g}$ of proteins); lanes 4 and 5 , fibroblasts of patient 1 ( 40 and $20 \mu \mathrm{g}$, respectively, of proteins); lanes 6 and 7, fibroblasts of patient 2 ( 40 and 20 $\mu \mathrm{g}$, respectively, of proteins).
Figure 6. Immunoblot analysis 
In both patients' cells, the contents of seven mitochondrial (short-, medium-, long-, very long-chain acyl-CoA dehydrogenase, short-chain enoyl-CoA hydratase, short-chain 3-hydroxyacyl-CoA dehydrogenase, and 3-ketoacyl-CoA thiolase) and two peroxisomal (bifunctional protein and 3-ketoacyl-CoA thiolase) enzymes were estimated by immunoblot analysis and found to be comparable to the amounts detected in control cells (data not shown).

Pulse-chase experiments. In cells from patient 1 (Fig. $7 \mathrm{~A}$, lanes $1-4$ of patient 1 ), the incorporation of $\left[{ }^{35} \mathrm{~S}\right]$ methionine into the $\alpha$ and $\beta$ subunits after a 1-h pulse labeling was 150 and $19 \%$, respectively, of those in the control cells, as determined by densitometric determination of the fluorographic bands. In the control cells, the signals for both $\alpha$ and $\beta$ subunits did not decrease after a 24-h chase (Fig. $7 A$, lanes $1-4$ of the control). However, the signals for both subunits in cells from patient 1

control patient 1 patient2

\section{4}
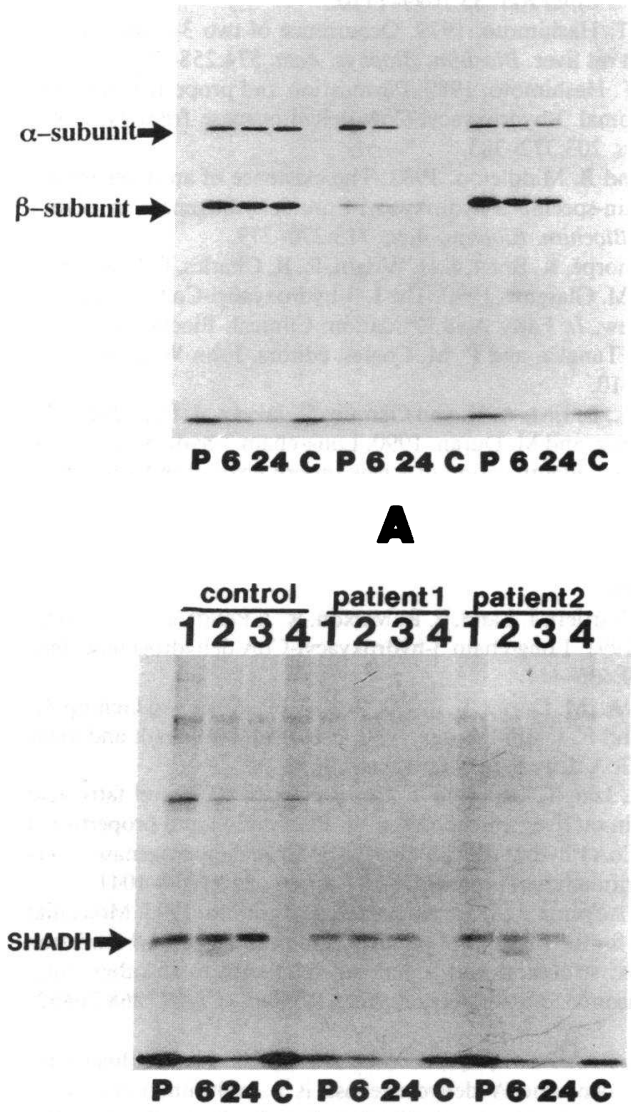

$\because$

Figure 7. Pulse-chase experiments of human-TP and short-chain 3hydroxyacyl-CoA dehydrogenase in fibroblasts. $(A)$ Human-TP; $(B)$ short-chain 3-hydroxyacyl-CoA dehydrogenase. Lane 1, 1-h pulse $(P)$; lanes 2 and 3, 6- (6) and 24-h chase (24), respectively; lane 4, competition experiment of $1-\mathrm{h}$ pulse $(C)$. Arrows indicate positions of the subunits of mature enzymes. Pulse-chase experiments using controls' and patients' fibroblasts were done three times, and incorporation of $\left[{ }^{35} \mathrm{~S}\right]$ methionine into protein of the fibroblasts was $69 \pm 8 \%(n=4), 71 \pm 1 \%$, and $77 \pm 2 \%$ in the controls, patient 1 , and patient 2 , respectively.

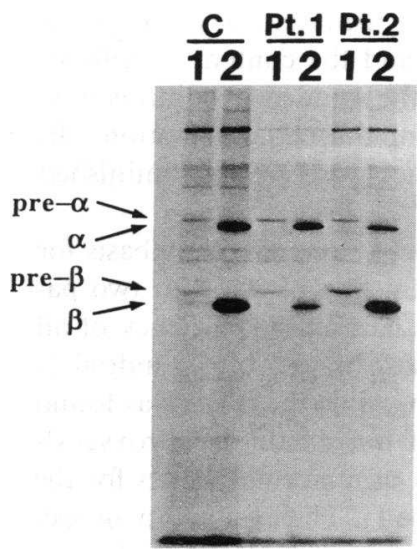

Figure 8. Pulse labeling experiments of human-TP in fibroblasts in the presence and absence of R6G. Lane 1, in the presence of $\mathrm{R} 6 \mathrm{G}$; lane 2 , in the absence of R6G. Control $(C)$, patient $1(P t .1)$, patient $2(P t$. 2). Arrows indicate positions of the fluorographic bands for the precursor of $\alpha$ subunit (pre- $\alpha)$, precursor of $\beta$ subunit (pre- $\beta$ ), $\alpha$ subunit $(\alpha)$, and $\beta$ subunit $(\beta)$ of the enzyme. Competition experiments determined positions of the precursors (data not shown).

did decrease and became faint after a 24-h chase. In cells from patient 2 (Fig. $7 A$, lanes $1-4$ of patient 2 ), the radioactivity in the $\alpha$ and the $\beta$ subunits after a 1-h pulse labeling was 70 and $120 \%$, respectively, of that in the control cells. Thus, both subunits in cells from patient 2 were degraded more rapidly than in the control cells, the value being $\sim 50 \%$ of that in the control cells after a 24-h chase. These findings suggest that the rates of synthesis and degradation of the enzyme in the patients' cells were altered. Fluorographic analysis of mitochondrial shortchain 3-hydroxyacyl-CoA dehydrogenase was made as the positive control, using the same samples (Fig. $7 B$ ).

Fig. 8 shows the results of pulse labeling experiments in the presence and absence of rhodamine $6 \mathrm{G}$ (R6G). In the absence of $\mathrm{R} 6 \mathrm{G}$, the fluorographic bands corresponding to the mature forms of the $\alpha$ and $\beta$ subunits were apparent in cells from control and patients (Fig. 8, lanes 2 ). In the presence of R6G, precursors of the $\alpha$ and $\beta$ subunits were clearly observed in the control and patients' cells (Fig. 8, lanes 1 ). These data suggest that both the $\alpha$ and $\beta$ subunits in the two patients' cell lines were synthesized in their correct precursor forms and with the same size as in the controls. Furthermore, the data of Fig. 8 suggest that the precursors were imported normally into the mitochondria and were subsequently processed to be followed by rapid degradation.

Oxidation of $\left[1-{ }^{14} \mathrm{C}\right]$ palmitic acid. Oxidation of $\left[1-{ }^{14} \mathrm{C}\right]-$ palmitic acid to acid soluble products was quantitated as described earlier (33). $\left[1-{ }^{14} \mathrm{C}\right]$ Palmitate oxidations were decreased in fibroblasts from both patients to virtually the same extent, residual activities amounting to 32 and $31 \%$, respectively, (control values: $1.63 \pm 0.41 \mathrm{nmol} / \mathrm{h}$ per $\mathrm{mg}$ protein; $n$ $=6$ ). These results indicate that, in fibroblasts, TP plays an important role in long-chain fatty acid oxidation.

\section{Discussion}

Long-chain 3-hydroxyacyl-CoA dehydrogenase does not appear to be a monofunctional enzyme protein but rather part of a complex also harboring enoyl-CoA hydratase and 3-ketoacylCoA thiolase activities. Earlier, we purified this mitochondrial fatty acid oxidation multienzyme complex from rat liver (12) and named it "trifunctional protein." Previous biochemical findings indicated that this "trifunctional protein deficiency" can be divided into two groups. In group 1 there was significant diminution in long-chain 3-hydroxyacyl-CoA dehydrogenase 
activity (10). The major part of the trifunctional protein deficiency is included in this group, and the content of trifunctional protein in these patients is the same as in controls or is slightly diminished ( $T$. Kamijo, unpublished observation ). In group 2, all three enzyme activities were greatly diminished $(20,32)$.

In the present work, we analyzed the underlying basis for the enzyme defect in cultured skin fibroblasts from two patients, one suspected of having a combined deficiency of all three enzyme activities, as catalyzed by the mitochondrial $\beta$ oxidation multifunctional protein, while the other was found to have an isolated deficiency of long-chain 3-hydroxyacylCoA dehydrogenase activity with near normal values for the two other enzyme activities (Table I). The availability of specific antibodies raised against various monofunctional mitochondrial fatty acid $\beta$-oxidation enzyme proteins, as purified from rat liver, facilitated study on the trifunctional protein in fibroblasts from the patients. Results of immunoprecipitation experiments presented in Figs. 3-5 together with immunoblotting data in Fig. 6 clearly show that the trifunctional enzyme is defective in the fibroblasts from both patients, albeit the extent of dysfunction of trifunctional protein in these two cell lines was markedly different (Figs. 3-6).

When biosynthesis, import into mitochondria, and degradation of human-TP in cells from patient 1 were studied (Figs. 7 and 8 ), we found that biosynthesis of the two subunits, $\alpha$ and $\beta$, occurred at rates of 150 and $19 \%$, respectively, as compared with findings in control cells. Furthermore, the data indicate that the two subunits were normally imported into the mitochondria and processed, followed by a rapid rate of degradation. The rapid disappearance of the $\beta$ subunit, as compared with the $\alpha$ subunit, suggests that the $\beta$ subunit in cells from patient 1 is not normal with respect to biosynthesis and stability. Presumably, this leads to a disturbed formation of the enzyme complex resulting in lability of the $\alpha$ subunit as a secondary consequence.

In cells from patient 2 , the $\alpha$ and $\beta$ subunits were present at levels of $\sim 60 \%$, as compared with control cells, hence, formation of the $\alpha 4 \beta 4$-enzyme complex probably occurs normally in these cells. Interestingly, the 3-hydroxyacyl-CoA dehydrogenase activity in these cells was decreased to the same extent as in cells from patient 1 , with near normal activity of enoyl-CoA hydratase. Since the $\alpha$ subunit harbors both enoyl-CoA hydratase and 3-hydroxyacyl-CoA dehydrogenase activity, these results suggest that the mutation in patient 2 affects only the 3-hydroxyacyl-CoA dehydrogenase domain of TP. In agreement with the reduced amounts of trifunctional protein, as found by immunoblotting of fibroblasts from patient 2, 3-ketoacyl-CoA thiolase activities were found to be intermediate, as compared with the activities in cells from control and patient 1 , respectively. Figs. 7 and 8 show rates of synthesis of the $\alpha$ and $\beta$ subunits in patient 2 cells of 70 and $120 \%$, respectively, as compared with control cells, followed by normal import into mitochondria and processing. Interestingly, the $\beta$ subunit appeared to be degraded more rapidly in cells from patient 2 (Fig. 8).

We propose that the group 1-type trifunctional protein deficiency is caused by abnormality of the $\alpha$ subunit, while the group 2-type trifunctional protein deficiency is caused by abnormality of the $\beta$ subunit. The hypothesis based on primary structures deduced from nucleotide sequences of the subunits of the enzyme is that the $\alpha$ subunit of TP has enoyl-CoA hydratase plus 3-hydroxyacyl-CoA dehydrogenase activities and the $\beta$ subunit of TP harbors 3-ketoacyl-CoA thiolase activity (13).

\section{Acknowledgments}

We are grateful to $M$. Ohara for assistance with language and editing.

This study was supported by a grant-in-aid for Scientific Research (A) and a grant-in-aid for Scientific Research on Priority Areas from the Ministry of Education, Science and Culture of Japan, and a research grant for the Intractable Diseases from the Ministry of Health and Welfare of Japan.

\section{References}

1. Saudubray, J.-M., G. Mitchell, J.-P. Bonnefont, G. Schwarts, C. Nuttin, A. Munnich, M. Brivet, A. Vassault, F. Demaugre, D. Rabier, and C. Charpentier. 1992. Approch to the patient with a fatty acid oxidation disorder: a review. In New Developments in Fatty Acid Oxidation. P. M. Coates and K. Tanaka, editors. John Wiley \& Sons, Inc., New York. 271-288.

2. Rhead, W. J. 1991. Inborn errors of fatty acid oxidation in man. Clin. Biochem. 24:319-329.

3. Coates, P. M., and K. Tanaka. 1992. Molecular basis of mitochondrial fatty acid oxidation defects. J. Lipid Res. 33:1099-1110.

4. Osumi, T., and T. Hashimoto. 1979. Occurrence of two 3-hydroxyacylCoA dehydrogenases in rat liver. Biochim. Biophys. Acta. 574:258-267.

5. Osumi, T., and T. Hashimoto. 1980. Purification and properties of mitochondrial and peroxisomal 3-hydroxyacyl-CoA dehydrogenase from rat liver. Arch. Biochem. Biophys. 203:372-383.

6. El-Fakhri, M., and B. Middleton. 1982. The existence of an inner-membrane-bound, long-chain-specific 3-hydroxyacyl-CoA dehydrogenase in mammalian mitochondria. Biochim. Biophys. Acta. 713:270-279.

7. Hale, D. E., C. Thorpe, K. Braat, J. H. Wright, R. R. Charles, P. M. Coates, T. Hashimoto, and A. M. Glasgow. 1990. The L-3-hydroxyacyl-CoA dehydrogenase deficiency: a review. In Fatty Acid Oxidation: Clinical, Biochemical, and Molecular Aspects. K. Tanaka, and P. M. Coates, editors. John Wiley \& Sons, Inc., New York. 503-510.

8. Wanders, R. J. A., L. Ijlst, A. H. van Gennip, C. Jakobs, J. P. de Jager, L. Dorland, F. J. van Sprang, and M. Duran. 1990. Long-chain 3-hydroxyacyl-CoA dehydrogenase deficiency: identification of a new inborn error of mitochondrial fatty acid $\beta$-oxidation. J. Inherited Metab. Dis. 13:311-314.

9. Przyrembel, H., C. Jakobs, L. Ijlst, J. B. C. de Klerk, and R. J. A. Wanders. 1991. Long-chain 3-hydroxyacyl-CoA dehydrogenase deficiency. J. Inherited Metab. Dis. 14:674-680.

10. Jackson, S., K. Bartlett, J. Land, E. R. Moxon, R. J. Pollitt, J. V. Leonard, and D. M. Turnbull. 1991. Long-chain 3-hydroxyacyl-CoA dehydrogenase deficiency. Pediat. Res. 29:406-411.

11. Wanders, R. J. A., M. Duran, L. Ijlst, J. P. de Jager, A. H. van Gennip, C. Jakobs, L. Dorland, and F. J. van Sprang. 1989. Sudden infant death and longchain 3-hydroxyacyl-CoA dehydrogenase. Lancet. ii:52-53.

12. Uchida, Y., K. Izai, T. Orii, and T. Hashimoto. 1992. Novel fatty acid $\beta$-oxidation enzymes in rat liver mitochondria. II. Purification and properties of enoyl-coenzyme A (CoA) hydratase/3-hydroxyacyl-CoA dehydrogenase/3-ketoacyl-CoA thiolase trifunctional protein. J. Biol. Chem. 267:1034-1041.

13. Kamijo, T., T. Aoyama, J. Miyazaki, and T. Hashimoto. 1993. Molecular cloning of the cDNAs for the subunits of rat mitochondrial fatty acid $\beta$-oxidation multienzyme complex: structural and functional relationships to other mitochondrial and peroxisomal $\beta$-oxidation enzymes. J. Biol. Chem. 268:2645226460.

14. Carpenter, K., R. J. Pollitt, and B. Middleton. 1992. Human liver longchain 3-hydroxyacyl-coenzyme A dehydrogenase is a multifunctional membrane-bound beta-oxidation enzyme of mitochondria. Biochem. Biophys. Res. Commun. 183:443-448.

15. Furuta, S., S. Miyazawa, and T. Hashimoto. 1981. Purification and properties of rat liver acyl-CoA dehydrogenases and electron transfer flavoprotein. $J$. Biochem. 90:1739-1750.

16. Izai, K., Y. Uchida, T. Orii, and T. Hashimoto. 1992. Novel fatty acid $\beta$-oxidation enzymes in rat liver mitochondria: I. Purification and properties of very-long-chain acyl-coenzyme A dehydrogenase. J. Biol. Chem. 267:10271033.

17. Furuta, S., S. Miyazawa, T. Osumi, T. Hashimoto, and N. Ui. 1980. Properties of mitochondrial and peroxisomal enoyl-CoA hydratases from rat liver. J. Biochem. 88:1059-1070.

18. Miyazawa, S., T. Osumi, and T. Hashimoto. 1980. The presence of a new 3-oxoacyl-CoA thiolase in rat liver peroxisomes. Eur. J. Biochem. 103:589-596.

19. Osumi, T., and T. Hashimoto. 1979. Peroxisomal $\beta$-oxidation system of 
rat liver. Copurification of enoyl-CoA hydratase and 3-hydroxyacyl-CoA dehydrogenase. Biochem. Biophys. Res. Commun. 89:580-584.

20. Wanders, R. J. A., L. Ijlst, F. Poggi, J.-P. Bonnefont, A. Munnich, M. Brivet, D. Rabier, and J.-M. Saudubray. 1992. Human trifunctional protein deficiency: a new disorder of mitochondrial fatty acid $\beta$-oxidation. Biochem. Biophys. Res. Commun. 188:1139-1145.

21. Lynen, F., U. Henning, C. Bublitz, B. Sörbo, and L. Kröplin-Rueff. 1953. Der chemische Mechanismus der Acetessigsäurebildung in der Liver. Biochem. Z. 330:269-295.

22. Steinman, H. M., and R. L. Hill. 1975. Bovine liver crotonase. In Methods in Enzymology. John M. Lowenstein, editor. Academic Press, New York. 35:136-151.

23. Wieland, T., and L. Rueff. 1953. Synthese von S-b-oxybutyryl- und S-acetacetyl-coenzyme A. Angew. Chem. Int. Ed. Eng. 65:186-187.

24. Imamura, S., S. Ueda, M. Mizugaki, and A. Kawaguchi. 1990. Purification of the multienzyme complex for fatty acid oxidation from Pseudomonas fragi and reconstitution of the fatty acid oxidation system. J. Biochem. 107: 184-189.

25. Markwell, M. A. K., S. M. Haas, L. L. Bieber, and N. E. Tolbert. 1978. A modification of the Lowry procedure to simplify protein determination in membrane and lipoprotein samples. Anal. Biochem. 87:206-210.

26. Lowry, O. H., N. J. Rosebrough, A. L. Farr, and R. J. Randall. 1951.
Protein measurement with the Folin phenol reagent. J. Biol. Chem. 193:265275.

27. Laemmli, U. K. 1970. Cleavage of structural proteins during the assembly of the head of bacteriophage T4. Nature (Lond.). 227:680-685.

28. Towbin, H., T. Staehelin, and J. Gordon. 1979. Electrophoretic transfer of proteins from acrylamide gels to nitrocellulose sheets: procedure and some applications. Proc. Natl. Acad. Sci. USA. 76:4350-4354.

29. Yamaguchi, S., T. Orii, N. Sakura, S. Miyazawa, and T. Hashimoto. 1988. Defect in biosynthesis of mitochondrial acetoacetyl-CoA thiolase in cultured fibroblasts from a boy with 3-ketothiolase deficiency. J. Clin. Invest. 81:813-817.

30. Gear, A. R. L. 1974. Rhodamine 6G: a potent inhibitor of mitochondrial oxidative phosphorylation. J. Biol. Chem. 249:3628-3637.

31. Ikeda, Y., S. M. Keese, and K. Tanaka. 1985. Molecular heterogeneity of variant isovaleryl-CoA dehydrogenase from cultured isovaleric acidemia fibroblasts. Proc. Natl. Acad. Sci. USA. 82:7081-7085.

32. Jackson, S., R. S. Kler, K. Bartlett, H. Brigges, L. A. Bindoff, M. Pourfarzam, D. Gardner-Medwin, and D. M. Turnbull. 1992. Combined enzyme defect of mitochondrial fatty acid oxidation. J. Clin. Invest. 90:1219-1225.

33. Suzuki, Y., N. Shimozawa, S. Yajima, S. Yamaguchi, T. Orii, and T. Hashimoto. 1991. Effects of sodium 2-[5-(4-chlorophenyl)pentyl]-oxirane-2carboxylate (POCA) on fatty acid oxidation in fibroblasts from patients with peroxisomal diseases. Biochem. Pharmacol. 41:453-456. 